\title{
Procedimientos libres de aerosol ante COVID-19 en odontología pediátrica.
}

\section{Aerosol-free procedures against COVID-19 in pediatric dentistry.}

\author{
Kevin Juárez Casanova,* Armando González Solís, ${ }^{\ddagger}$ Héctor Ramón Martínez Menchaca ${ }^{\S}$
}

\section{RESUMEN}

A finales de 2019 se identificó el virus SARS-CoV-2 (por su significado en inglés Severe Acute Respiratory Syndrome Coronavirus 2) como agente etiológico de la COVID-19 (por su significado en inglés coronavirus disease 2019) en la ciudad de Wuhan, China. Debido a su rápida propagación al resto del mundo durante el primer trimestre del año 2020, la Organización Mundial de la Salud (OMS) la declaró pandemia mundial en marzo del mismo año. Por el potencial de contagio de COVID-19 se ha considerado que el entorno clínico en el que se desenvuelve la odontología puede ser de alto riesgo para el paciente, el odontólogo y sus asistentes si no se tienen las medidas de bioseguridad adecuadas. En un principio se vieron suspendidas las consultas regulares; sin embargo, al volver a la actividad laboral se han adaptado protocolos para el control de infecciones como reforzar el uso de barreras de protección y minimizar tratamientos que involucren aerosoles. La caries es uno de los principales motivos de consulta en la odontología pediátrica, por lo que en este escrito se sugieren algunos protocolos basados en la mínima invasión que prescinden de instrumental rotatorio para salvaguardar al paciente en riesgo de contagio, reduciendo el número de visitas y tiempo en consulta e incluso controlando algunos aspectos de salud bucal fuera de consulta clínica por medio de estrategias preventivas que pueden llevarse a cabo desde casa. Esto significa también mantener la tranquilidad por parte de los tutores del paciente ante la pandemia que se vive actualmente.

Palabras clave: COVID-19, odontología pediátrica, mínima invasión.

\section{ABSTRACT}

At the end of 2019, the Severe Acute Respiratory Syndrome Coronavirus 2 (SARS-CoV-2) was identified as the etiological agent of COVID-19 in the city of Wuhan China. Due to its rapid spread to the rest of the world during the first trimester of 2020, the WHO declared a global pandemic in March of the same year. Due to the contagion potential of COVID-19, it has been considered that the clinical environment in which dentistry operates may be in high risk for the patient if the appropriate biosafety measures are not taken, initially clinical practices were suspended. However, when returning to work, protocols have been adapted to the infection control procedures, reinforced the use of protective barriers, and minimize treatments that involve aerosols. Caries is one of the main reasons for consultation in Pediatric Dentistry, this article suggests some protocols based on minimal invasion that dispense with rotating instruments to safeguard the patient from the risk of contagion, reducing the number of visits and time in consultation and even controlling some aspects of the oral health outside the dental visit through preventive strategies that can be carried out from home. Modifications to Dental Home. This should include maintaining tranquility and calm on the part of the patient's tutors in the face of the pandemic that we are currently experiencing.

Keywords: COVID-19, pediatric dentistry, minimal invasion

\section{INTRODUCCIÓN}

$\mathrm{E}$ I recién identificado virus SARS-CoV-2 (por su significado en inglés Severe Acute Respiratory Syndrome
Coronavirus 2) se ha descrito como el agente etiológico de la enfermedad por coronavirus de 2019 (COVID-19), la cual dio inicio a una pandemia en la ciudad de Wuhan, China a finales del último bimestre de 2019. Se cree que

\footnotetext{
* Residente especialidad de Odontología Pediátrica, Universidad Anáhuac Mayab.

₹ Coordinador en la especialidad de Odontología Pediátrica, Universidad Anáhuac Mayab.

$\S$ Department of Orthodontics, Pediatric Dentistry and Special Care, University of Louisville School of Dentistry, Louisville, Kentucky, USA.

Recibido: 22 de octubre de 2020. Aceptado para publicación: 11 de noviembre de 2020.

Citar como: Juárez CK, González SA, Martínez MHR. Procedimientos libres de aerosol ante COVID-19 en odontología pediátrica. Rev ADM. 2020; 77 (6): 301-305. https://dx.doi.org/10.35366/97618
} 
uno de los factores que pudiesen haber influido en la propagación del virus es la actividad aeroportuaria de la ciudad, pues posee uno de los aeropuertos internacionales más grandes de China con conexiones directas con varias de las principales ciudades del mundo, incluidas algunas de Latinoamérica. Debido a su errática expansión fuera del territorio chino, la transmisión de este virus se convirtió en un problema de salud pública a nivel mundial. ${ }^{1-3}$

El 30 de enero de 2020 la Organización Mundial de la Salud (OMS) declaró como emergencia de salud pública internacional la situación ante el coronavirus, advirtiendo sobre las posibles consecuencias y repercusiones que podrían tener los países donde se presente el virus. Con el paso de las semanas, la enfermedad se extendió y traspasó fronteras, notificándose su presencia en distintas regiones del mundo, para el 11 de marzo se declaró oficialmente como pandemia por parte de la OMS. ${ }^{3}$

Fue cuestión de tiempo para que el virus se detectara en Latinoamérica. El 25 de febrero se confirmó el primer caso en Brasil, el 28 de febrero en México, mientras que en Perú se registró el primer caso el 06 de marzo. La mayoría de los casos están asociados con individuos procedentes de Europa, específicamente de Italia. ${ }^{3}$

Estudios describen que todo individuo está sujeto contraer el virus. La OMS menciona que los principales síntomas del COVID-19 son fiebre (temperatura corporal superior a $38{ }^{\circ} \mathrm{C}$ ), tos seca y fatiga. Otros síntomas que pudiesen presentarse son dolores y malestares, congestión nasal, dolor de cabeza, conjuntivitis, pérdida de gusto y olfato, entre otros. Estos síntomas pudiesen llegar a progresar a una neumonía severa. El riesgo de mortalidad se ha observado en personas con compromiso sistémico (diabetes, cardiopatías, hipertensión, problemas respiratorios crónicos y cáncer. ${ }^{4}$

Con respecto a los pacientes infantiles, el SARS-COV-2 parece ser más benevolente que en adultos. La infección se basa en tres estadios principales: enfermedad leve (similar al resfriado), síndrome respiratorio moderado y neumonía intersticial grave. También se ha descrito que los niños en su mayoría presentan síntomas leves o incluso pueden ser asintomáticos cuando son mayores de la edad preescolar y carecen de inmunosupresión o enfermedades sistémicas. Sin embargo, aun siendo asintomáticos, sigue existiendo un riesgo de contagio. 5,6

La sintomatología previamente descrita puede tener diferentes niveles de compromiso (asintomática, severa y crítica). El periodo de incubación es de hasta 14 días y los síntomas pudiesen aparecer en promedio alrededor del sexto día. ${ }^{7}$

El modelo de transmisión de este nuevo coronavirus y su virulencia implican contagio humano de forma directa e indirecta, propagándose a través de saliva, gotas y fluidos respiratorios de pacientes enfermos de COVID-19.2,5

Durante la pandemia tanto niños como adultos deben ser considerados potencialmente infecciosos y debido a la forma de propagación del virus, trabajadores de la salud, así como sus procedimientos médicos y en particular estomatológicos, tienen gran riesgo de desarrollar una infección cruzada al generar aerosoles que se asocian a la transmisión de enfermedades respiratorias. ${ }^{6}$

Cabe aclarar que el COVID-19 no sólo se transmite por medio de los aerosoles, también a través del contacto con superficies de equipos, instrumental y mobiliario, ya que puede tener un alcance de hasta dos metros, pudiendo albergar al virus hasta por 72 horas. De igual forma, el virus puede destruirse de inmediato con desinfectantes como hipoclorito de sodio, agua y jabón y peróxido de hidrógeno. $1,7,8$

El profesional de salud oral se encuentra en un constante riesgo debido a la proximidad física con el paciente, al uso continuo de instrumental generador de aerosoles, exposición a microorganismos patógenos, sangre, saliva y virus presentes en la boca y tracto respiratorio, pudiendo inhalar el aerosol contaminado, entrar en contacto con la piel o mucosa y permanecer en las superficies del consultorio. ${ }^{1,5,9}$

El objetivo de este escrito es resumir algunas alternativas que pueden utilizarse en la práctica de odontología pediátrica sin correr altos riesgos de transmisión de COVID-19 generados por aerosoles contaminados y disminuir la propagación del virus.

\section{BIOSEGURIDAD}

En fechas recientes, además de la Norma Oficial Mexicana NOM-013-SSA2-2015, encargada de la prevención y control de enfermedades, las asociaciones dentales como la Asociación Dental Americana (ADA por sus siglas en inglés), la Academia Americana de Odontología Pediátrica (AAPD por sus siglas en inglés) y en México, la Asociación Dental Mexicana (ADM) han hecho recomendaciones para la práctica dental durante la pandemia. Se han detallado instrucciones que destacan la importancia de minimizar la infección cruzada, mantener la seguridad del profesional dental, los pacientes pediátricos, tutores y el uso adecuado del equipo de protección personal (EPP) antes, durante y después de la consulta dental. ${ }^{6,9}$

En un principio se indicó posponer las consultas ordinarias y únicamente atender casos de urgencia, además del uso de tecnologías para realizar orientación y consultas en línea ante pequeñas problemáticas que pudiesen 
resolverse por este medio. Sin embargo, al reanudarse las actividades laborales, se ha implantado la toma de temperatura, desinfección y encuestas rápidas sobre el estado general del paciente, descartando algún síntoma en todos los pacientes como proceso de rutina antes de la atención clínica. ${ }^{4,9}$

Dicho esto, y considerando que la mayoría de los pacientes infantiles pueden ser asintomáticos, todos los pacientes deben ser tratados como si estuvieran contaminados. ${ }^{4}$

Por tal motivo, los protocolos de atención se han visto modificados. Por ejemplo, la guía ante la crisis del COVID-19 de la ADA enfatiza el uso de aislamiento absoluto con dique de hule (el cual puede reducir hasta en $70 \%$ las partículas del aire), el uso de succión de alta potencia y reducir el uso de instrumental que genere aerosoles, sin descuidar la atención y la calidad de cada tratamiento. De igual forma se sugiere el uso de colutorios previo al tratamiento para minimizar la virulencia y contaminación con agentes oxidantes como el peróxido de hidrógeno al $1 \%$ o la yodopovirona al $2 \%$. $2,4,5,10$

\section{Protocolos libres de aerosol}

Debido a que la caries es el principal motivo por el cual acuden a consulta los pacientes infantiles, se ha optado por recurrir a tratamientos no invasivos o de mínima invasión que no incluyan el uso de piezas de mano y por consiguiente, evitar generar aerosol, de esta manera se asegura que la atención dental continúe con eficacia durante tiempos de la pandemia por COVID-19. Estos protocolos libres de aerosol incluyen la detección oportuna, evaluación de riesgo de caries y procedimientos no quirúrgicos. Para cumplir estos objetivos se recurre a la colocación de selladores, tratamientos de remineralización mediante el uso de barniz de flúor, resinas infiltrativas, técnica restaurativa atraumática (TRA), técnica de Hall y estrategias de prevención. 4,6,11-13

\section{Tratamientos mínimamente invasivos}

Además de promover el uso y aplicación de vehículos fluorados, los tratamientos de mínima invasión pretenden hacer énfasis en la prevención mediante el conocimiento de la etiología de la enfermedad, disminuyendo los factores de riesgo que propician el desarrollo de la caries y de la placa dental, orientando al paciente a partir de medidas dietéticas e higiénicas. Es importante recalcar que el éxito de estos procedimientos no operatorios depende del compromiso y disciplina del paciente y sus tutores. ${ }^{11,14,15}$

\section{Evaluación de riesgos}

Se hace hincapié en todos los factores que contribuyen al desarrollo de la caries (factores de ataque) y todos los factores que, según los estudios, evitan la enfermedad (factores de defensa). La evaluación de dicho equilibrio no sólo ayuda a establecer el nivel de riesgo de cada paciente, sino que sugiere las estrategias correctas para prevenir o revertir el proceso. Uno de los instrumentos más conocidos para evaluar es el sistema CAMBRA que presenta tres categorías mediante las cuales se clasifica el riesgo cariogénico del paciente (leve, moderado, severo). ${ }^{12,16}$

\section{Control de dieta}

La modificación benéfica de la biopelícula puede implicar la remoción o sustitución de elementos conducentes a la caries dental como los carbohidratos de la dieta. ${ }^{17}$ Además el control de dieta influirá tanto en la salud oral como en la salud general del niño, ya que el exceso de azúcares también supone mayor riesgo de padecer obesidad. Es importante adaptarse a cada etapa para poder proporcionar la mejor orientación con respecto a la alimentación, por ejemplo, promover la lactancia materna y mencionar que por sí sola no es cariogénica o disminuir el frecuente consumo de bebidas azucaradas en adolescentes. ${ }^{18,19}$

\section{Control de placa}

El control y/o eliminación de placa bacteriana (biofilm microbiano) por medios físicos, como la correcta práctica de técnicas de cepillado, el uso de complementos como cepillos interproximales e hilo dental así como medios químicos de alta aceptación como pastas dentales (5,000 ppm), reveladores de placa y enjuagues fluorados, tienen una influencia significativa con la presencia, prevalencia, incidencia y desarrollo de lesiones cariosas. Aunque la clorhexidina no es primera elección contra el SARS-COV-2, su uso y el de los enjuagues bucales se recomiendan de forma estricta para reducir el número de microorganismos orales. La aplicación de estos medios no requiere salir de casa, pero es importante asesorar al paciente. ${ }^{2,11,15,18}$

\section{Remineralización}

El concepto de remineralización se desarrolló en los años 70 y ha ido evolucionando hasta el día de hoy, no sólo en la fluorización de alimentos y pastas dentales, sino 
también incorporando el ion flúor con otros elementos que potencializan sus propiedades. ${ }^{15,17}$

El fluoruro diamino de plata al $38 \%$ es una sustancia líquida con propiedades remineralizantes, desensibilizantes y cariostáticas para lesiones cavitadas en dentición temporal, en un inicio se aplicaba en pacientes con extremo riesgo cariogénico, poco tolerantes a procedimientos convencionales o sistémicamente comprometidos. En la actualidad su uso ha ido ganando terreno, sobre todo por ser un método que prescinde totalmente del instrumental rotatorio. Aunque no es de apariencia estética al colocarlo en las lesiones, se ha priorizado sobre el uso del barniz de flúor. 4,6,20,21

El barniz de fluoruro de sodio al 5\% aplicado en consultorio trimestral o semestralmente también ha tenido resultados satisfactorios, aunque su éxito se limita a prevención y remineralización de lesiones incipientes o no cavitadas para evitar su progreso. Su uso proporciona mayor beneficio cuando se emplea en combinación con otros tratamientos como los selladores de fosetas y fisuras. ${ }^{4,11,21}$

\section{Selladores de fosas y fisuras}

Al igual que el barniz de flúor, los selladores pueden ser más efectivos en lesiones superficiales y oclusales; algunas investigaciones sugieren que pueden permanecer hasta 10 años en dientes permanentes, de igual forma puede detener o impedir el desarrollo de caries en dientes primarios y permanentes. Para este tratamiento existen resinas fluidas de alta carga y cementos de ionómero de vidrio, no hay diferencia significativa en ellos y no requieren el uso de instrumental rotatorio. ${ }^{4,6,15,21}$

\section{Resinas infiltrativas}

El tratamiento de resinas infiltrativas se desarrolló en Alemania, es una técnica ultraconservadora, se indica para detener lesiones de esmalte y dentina no cavitadas que se encuentren en superficies tanto vestibulares como interproximales, aplaza el desarrollo de caries y puede eliminar la necesidad de un tratamiento quirúrgico. Debido a que es un tratamiento microabrasivo, se evita en dientes con defectos de estructura y de dentina expuesta, su éxito es superior en conjunto al uso de barniz de flúor. ${ }^{14-16,22,23}$

\section{Tratamiento restaurador atraumático}

El tratamiento restaurador atraumático (TRA) surgió en Brasil, y está respaldado por la OMS como técnica contemporánea y mínimamente invasiva por excelencia. Se desarrolló para tratar, restaurar y prevenir caries en poblaciones de países en vías de desarrollo y con acceso limitado a una atención dental tradicional; sin embargo, su aplicación ha trascendido fronteras debido al éxito que han reportado diversos estudios. ${ }^{11,15}$

Consiste en remover tejido duro infectado por medio de instrumentos no rotatorios que permiten ser más selectivos y conservadores y en ocasiones con ayuda de agentes químicos como la papaína, la cual tiene la propiedad de remover la colágena necrosada de la dentina, por lo que prescinde totalmente del instrumental generador de aerosoles. Otro punto a favor de esta técnica es que en $82 \%$ de los casos no es necesario colocar anestesia local, reduciendo la ansiedad que pudiese generar en el paciente. ${ }^{14-16}$

Posterior a la remoción del tejido, se realiza obturación con un material bioactivo y biocompatible como el ionómero de vidrio, el cual también promueve la remineralización interna del diente por medio de la liberación del flúor que lo compone. ${ }^{24}$ Es importante recalcar que se debe seleccionar y evaluar cada caso para poder obtener los mejores resultados en el tratamiento. ${ }^{15}$

\section{Técnica de Hall}

Se ha recurrido a esta técnica principalmente para tratar molares deciduos con presencia de caries profundas o extensas, pero absueltos de compromiso o daño pulpar. Consiste en sellar las lesiones colocando una corona de acero cromo convencional a modo de presión, cementada con ionómero de vidrio, sin la necesidad de hacer uso de anestésico local, preparación dentaria ni remoción de caries, por lo que se evita totalmente el uso de piezas de mano, para ello es necesario crear espacio de tres a cinco días con ligas separadoras de ortodoncia previo al tratamiento. $6,11,25$

Suele haber un efecto en el músculo masetero y en la oclusión, elevando ligeramente la mordida, pero ésta se resuelve de forma espontánea después de cerca de un mes. Aunque se ha discutido su aplicación, también se ha respaldado con estudios que han demostrado éxito después de 2.5 años. Al igual que la técnica TRA, es de suma importancia realizar un diagnóstico correcto y una selección adecuada del caso. 6,11

\section{CONCLUSIÓN}

El surgimiento de la COVID-19 ha repercutido de forma importante en la práctica odontológica, pues se ha reportado que existe alto riesgo de transmisión en el entorno dental, razón por la que se debe reforzar la bioseguridad 
del consultorio, modificando y adaptando nuestros protocolos clínicos al realizar tratamientos que prescindan o reduzcan el uso de instrumental rotatorio o generadores de aerosol como los que ofrece la mínima invasión.

En la odontología pediátrica hay un íntimo contacto con la mínima invasión para el tratamiento de la caries, que es el principal motivo de consulta en el área y que se enfocan desde la prevención y control de lesiones hasta procedimientos que eliminen o impidan el desarrollo de la enfermedad, por lo que es importante resaltar estas técnicas para cubrir las necesidades del paciente sin suponer un riesgo en tiempos de pandemia. Además de ofrecer un amplio espectro para la inclusión de los casos, pues por sus características son técnicas que reducen la estancia del paciente en el sillón dental, favorece la cooperación del mismo cuando hay ansiedad, poca tolerancia o necesidades especiales y por consiguiente, una buena aceptación de parte de los padres o tutores.

\section{BIBLIOGRAFÍA}

1. Sigua-Rodriguez EA, Bernal-Pérez JL, Lanata-Flores AG et al. COVID-19 y la Odontología: una Revisión de las recomendaciones y perspectivas para Latinoamérica. Int. J. Odontostomat. 2020; 14 (3): 299-309.

2. Suárez SS, Campuzano R, Dona VM, Garrido CE, Gimenez MT. Recomendaciones para prevención y control de infecciones por SARSCoV-2 en odontología. Revista Odontología. 2020; 22 (2): 5-32.

3. Rodríguez-Morales AJ, Sánchez-Duque JA, Hernández Botero S, Pérez-Díaz CE, Villamil-Gómez WE, Méndez CA et al. Preparación y control de la enfermedad por coronavirus 2019 (COVID-19) en América Latina. Acta Med Peru. 2020; 37 (1): 3-7.

4. Amorim LM, Maske TT, Ferreira SH, Santos RB, Feldens CA, Kramer PF. New post-COVID-19 biosafety protocols in pediatric dentistry. Pesqui Bras Odontopediatria Clín Integr. 2020; 20 (Supp1): e0117.

5. Bahramian H, Gharib B, Baghalian A. COVID-19 Considerations in pediatric dentistry. JDR Clin Trans Res. 2020; 5 (4): 307-311.

6. Al-Halabi M, Salami A, Alnuaimi E, Kowash M, Hussein I. Assessment of paediatric dental guidelines and caries management alternatives in the post COVID-19 period. A critical review and clinical recommendations. Eur Arch Paediatr Dent. 2020; 21 (5): 543-556.

7. Orellana-Centeno JE, Morales-Castillo V, Guerrero SRN. Generalidades, manejos, cuidados y manifestaciones clínicas del SARS-CoV-2. Rev ADM. 2020; 77 (3): 153-155.

8. Orellana-Centeno JE, Morales-Castillo V, Guerrero SRN. Coronavirus (SARS-CoV-2) y el entorno odontológico. Rev ADM. 2020; 77 (2): 84-87.

9. Cavazos-López EN, Flores-Flores DA, Rumayor-Piña A et al. Conocimiento y preparación de los odontólogos mexicanos ante la pandemia por COVID-19. Rev ADM. 2020; 77 (3): 129-136.

10. American Dental Association. Summary of ADA guidance during the COVID-19 crisis. Available in: https://success.ada.org/ /media/ CPS/Files/COVID/COVID-19_Int_Guidance_Summary.pdf.
11. Cagetti MG, Angelino E. Could SARS-CoV-2 burst the use of NonInvasive and Minimally Invasive treatments in paediatric dentistry? Int J Paediatr Dent. 2020; 00: 1-4.

12. Whitehouse JA. Bienvenidos al mundo de la odontología mínimamente invasiva. Journal of Minimum Intervention in Dentistry. 2009; 2: 270-272.

13. Benzian H, Niederman R. A dental response to the COVID-19 pandemic-Safer Aerosol-Free Emergent (SAFER) Dentistry. Front Med (Lausanne). 2020; 7: 520

14. Hayes M, Allen E, da Mata C, McKenna G, Burke F. Minimal intervention dentistry and older patients part 2: minimally invasive operative interventions. Dent Update. 2014; 41 (6): 500-505.

15. Ariño $P$, Ariño $P$, Ariño $B$, Cervadoro A, Ariño L. Tratamiento biológico de la caries: Odontología mínimamente invasiva o de mínima intervención. Gaceta Dental. 2014; 263: 149-166.

16. Chaple Gil, Alain Manuel. Generalidades sobre la mínima intervención en Cardiología. Revista Cubana de Estomatología. 2016; 53 (2): 37-44.

17. Portilla RJ, Pinzón TME, Huerta LER et al. Conceptos actuales e investigaciones futuras en el tratamiento de la caries dental y control de la placa bacteriana. Rev Odont Mex. 2010; 14 (4): 218-225.

18. González SA, González NB, González NE. Salud dental: relación entre la caries dental y el consumo de alimentos. Nutrición Hospitalaria. 2013; 28 (4): 64-71.

19. Cantú-Solís E et al. Caracterización de la flora bucal según patrón de amamantamiento en un grupo de madres e hijos. Revista ADM. 2015; 72 (3): 146-152.

20. Non-restorative cavity treatment: should this be the treatment of choice? reflections of a teacher in paediatric dentistry. Dental Update. 2019; 46 (3): 220-228.

21. Urquhart O, Tampi MP, Pilcher L et al. Nonrestorative treatments for caries: systematic review and network meta-analysis. J Dent Res. 2019; 98 (1): 14-26.

22. Nahuelhuaique FP, Díaz MJ, Sandoval VP. Resinas infiltrantes: un tratamiento eficaz y mínimamente invasivo para el tratamiento de lesiones blancas no cavitadas. Revisión narrativa. Av Odontoestomatol. 2017; 33 (3): 181-186.

23. Zalba J. Técnica De Restauración Atraumática (ART) en la odontología de mínima intervención. Revista Labor Dental. 2009; 13 (48): 174-176.

24. Díaz JA, Jans A, Zaror C. Efectividad de la remoción parcial de caries en molares primarios con lesiones de caries profunda. Ensayo clínico aleatorizado. Int J Odontostomat. 2017; 11 (4): 443-449.

25. Midani R, Splieth $\mathrm{CH}$, Mustafa Ali M, Schmoeckel J, Mourad SM, Santamaria RM. Succes rates of preformed metal crowns placed with the modified and standard hall technique in a paediatric dentistry setting. Int J Paediatr Dent. 2019; 29 (29): 550-556.

Correspondencia:

Kevin Juárez Casanova

E-mail: kevin_jz@outlook.com

Conflicto de intereses: Los autores declaran no tener ningún conflicto de intereses. 